\section{JURNAL EKONOMI EFEKTIF}

ISSN : $2622-8882$, E-ISSN : 2622-9935

Jurnal Ekonomi Efektif, Vol. 2, No. 3, April 2020

@Prodi Manajemen Fakultas Ekonomi Universitas

Pamulang

\title{
PENGARUH PROMOSI TERHADAP KEPUTUSAN MEMILIH SEKOLAH PADA ORANGTUA SISWA SDIT BINA CENDEKIA - DEPOK
}

\author{
Munarsih $^{1 *}$, Mada Faisal Akbar ${ }^{2}$, Agus Sudarsono ${ }^{3}$ \\ Universitas Pamulang \\ dosen02448@unpam.ac.id*
}

\begin{abstract}
ABSTRAK
Tujuan penelitian ini adalah untuk mengetahui pengaruh promosi terhadap peningkatan jumlah siswa pada tahun ajaran baru di SDIT Bina Cendekia. Metode yang digunakan adalah metode deskriptif kuantitatif. Teknik sampling yang digunakan adalah random sampling menggunakan sampel jenuh sebanyak 143 responden. Analisis data menggunakan Uji Validitas, Uji Reliabilitas Instrumen, Uji Korelasi Product Moment, Uji Regresi Sederhana, Uji Koefisien Determinasi dan Uji Hipotesis. Hasil penelitian adalah Terdapat Pengaruh Positif dan Signifikan antara Promosi Sekolah (X) terhadap Minat Sekolah (Y) pada SDIT Bina Cendekia. Persamaan regresi sederhana $\mathrm{Y}=\mathrm{a}+\mathrm{b}(\mathrm{x})$ adalah $\mathrm{Y}=21,07=$ 0,76x persamaan ini dapat disimpulkan Bahwa Terdapat Arah Pengaruh Positif Antara Variabel Promosi Sekolah (X) Terhadap Variabel Minat Sekolah (Y). Constanta a = 28,03 bermakna, jika tidak ada perubahan pada variabel Promosi Sekolah $(X)$ atau variabel bebas bernilai tetap, maka nilai variabel Minat Sekolah (Y) sebesar 21,07. Koefisien regresi $b=0,755$ bermakna, jika terjadi kenaikan satusatuan pada variabel Promosi Sekolah (X) maka nilai Variabel Minat Sekolah (Y) akan bertambah sebesar 0,766. Koefisien korelasi R sebesar 0,529 nilai ini masuk ke dalam rentang antara 0,400 - 0,599 dengan tingkat hubungan sedang, maka dapat disimpulkan bahwa, variabel Promosi Sekolah (X) memiliki tingkat hubungan Sedang terhadap variabel Minat Sekolah (Y). Koefisien determinasi R Square sebesar 0,4298 $(0,1848 \times 100 \%=18,48 \%)$ maka dapat disimpulkan bahwa, Promosi Sekolah(X) memiliki Kontribusi atau sumbangan terhadap Minat Sekolah (Y) sebesar 18,48\% dan sisanya 81,52\% dipengaruhi oleh faktor lain yang tidak diteliti. Uji hipotesis parsial menunjukkan nilai thitung 5,6528 > $\mathrm{t}_{\text {tabel }}$ 1,977 dengan taraf $5 \%$ maka $\mathrm{H}_{\mathrm{a}}$ diterima dan $\mathrm{H}_{0}$ ditolak maka dalam penelitian ini menetapkan bahwa Terdapat Pengaruh Positif dan Signifikan antara Promosi Sekolah (X) terhadap Minat Sekolah (Y) pada SDIT Bina Cendekia.
\end{abstract}

Kata Kunci : Promosi, Keputusan Memilih Sekolah. 


\begin{abstract}
The purpose of this study was to determine the effect of promotion on increasing the number of students in the new school year at SDIT Bina Cendekia. The method used is quantitative descriptive method. The sampling technique used was random sampling using a saturated sample of 143 respondents. The data analysis using Validity Test, Instrument Reliability Test, Product Moment Correlation Test, Simple Regression Test, Determination Coefficient Test and Hypothesis Test. The results of the studies are a Positive and Significant Effect between School Promotion (X) on School Interest $(Y)$ on SDIT Bina Cendekia. Simple regression equation $Y=a+b(x)$ is $Y=21.07=0.76 x$ this equation can be concluded that a Positive Influence Direction Between School Promotion Variables (X) Against School Interest Variables $(Y)$. Constanta $a=28.03$ is meaningful, if there is no change in the variable School Promotion $(X)$ or the independent variable has a fixed value, then the value of the School Interest variable $(Y)$ is 21.07. Regression coefficient $b=0.755$ means, if there is a one-unit increase in the variable School Promotion $(X)$ then the value of School Interest Variables $(Y)$ will increase by 0.766. $R$ correlation coefficient of 0.529 this value entered into the range between 0.400 to 0.599 with a moderate level of relationship, it can be concluded that, the variable School Promotion (X) has a moderate level of relationship with the variable School Interest $(Y)$. R Square determination coefficient of $0.4298(0.1848 \times 100 \%=18.48 \%)$ it can be concluded, School Promotion $(X)$ has a Contribution or contribution to School Interest $(Y)$ of $18.48 \%$ and the remaining $81,52 \%$ are influenced by other factors not examined. The partial hypothesis test shows the value of tcount 5.6528> t table 1.977 with a level of 5\%, then Ha is accepted and $\mathrm{HO}$ is rejected, so in this study there are a Positive and Significant Effect between School Promotion (X) on School Interest (Y) at SDIT Bina Cendekia.
\end{abstract}

\title{
Keywords: Promotion, Decision to Choose the School.
}




\section{PENDAHULUAN}

\section{A. Latar Belakang Masalah}

Sekolah Dasar Islam Terpadu atau SDIT adalah sekolah bagi Warga Negara Indonesia yang beragama Islam. Sekolah ini dapat digabungkan dalam dua metode pendidikan yaitu pendidikan reguler dan pendidikan aqidah/agama Islam. Dalam pendidikan reguler, mata pelajaran yang diajarkan sama seperti sekolah pada umumnya yaitu Matematika, IPA (Ilmu Pengetahuan Alam), Bahasa Indonesia, dan lain-lain. Sedangkan dalam pendidikan aqidah/agama Islam materi yang diajarkan berbeda dengan sekolah pada umumnya, seperti: tahfiz, hadist, BTQ/Baca Tulis Qur'an, dan sebagainya. Sehingga, waktu yang diperlukan lebih lama dibandingkan dengan lembaga sekolah lain, seperti: SDN, lembaga kursus, bimbingan belajar, dan lain-lain.

SDIT Bina Cendekia yang beralamat di Jl. Curug Raya, Rt 01/09, Kel. Curug, Kec. Bojongsari, Depok-Jawa Barat (16517). Didirikan pada tahun 2009/2010 oleh Yayasan Ar Romli Ibnu Tisan - Depok. Beroperasional tahun 2010/2011 dengan luas tanah $1105,8 \mathrm{~m}^{2}$ beserta luas bangunan $720,55 \mathrm{~m}^{2}$.

SDIT ini memiliki program unggulan yang dinamakan 3T yaitu Tahsin, Tahfidz dan Talaqqi. Dalam metode ini, peserta didik diwajibkan untuk menghafal Al-Qur'an selama kegiatan pembelajaran dan dibimbing oleh guru mata pelajaran agar dapat menempuh target hapalan Al-Qur'an yaitu 3 juz, diantaranya juz 28, 29, dan juz 30.

Kotler dan Keller (2009:36) menyatakan bahwa sektor pemerintah, dengan pengadilan, jasa penyedia lapangan kerja, rumah sakit, lembaga peminjaman, jasa militer, kepolisian dan pemadam kebakaran, jasa pos, lembaga peraturan, dan sekolah adalah bisnis jasa. Dengan pernyataan tersebut, menunjukkan bahwa pendidikan merupakan salah satu bisnis jasa.

Ali Hasan (2014:89) menyatakan bahwa disaat persaingan semakin ketat, produsen berusaha memenuhi kebutuhan dan keinginan konsumen dengan menawarkan berbagai jenis produknya, dampaknya konsumen mempunyai banyak pilihan, kekuatan tawar menawar konsumen semakin besar, yang mendorong setiap perusahaan harus menempatkan orientasinya pada kepuasan pelanggan sebagai tujuan utamanya. Produsen yakin bahwa: 1) kunci sukses untuk memenangkan persaingan terletak pada kemampuan memberikan total customer value yang dapat memuaskan pelanggan melalui penyampaian produk yang berkualitas dan harga bersaing, 2) kepuasan akan mengarahkan orang untuk mengulangi pembelian dan melakukan rekomendasi word of mouth positive.

Promosi yang dilakukan oleh pihak sekolah merupakan salah satu sumber informasi yang dapat mempengaruhi siswa untuk memilih sekolah. Sebagai sumber informasi, promosi akan berupa pengetahuan baru mengenai rincian detail sekolah yang diperlihatkan melalui gambar dan keterangan. Informasi ini akan diproses dengan pengalaman yang dimiliki baik dari diri sendiri maupun dari orang lain. Sehingga, akan menentukan penilaian terhadap SDIT Bina Cendekia. Jika promosi yang diberikan sekolah dapat menarik minat calon siswa baru, akan berkelanjutan terhadap keputusan orangtua siswa untuk memilih SDIT Bina Cendekia..Berdasarkan pada latar belakang masalah diatas, maka penelitian ini dilakukan dengan menetapkan judul "Pengaruh Promosi terhadap Keputusan Memilih Sekolah pada Orangtua Siswa SDIT Bina Cendekia - Depok."

\section{B. Rumusan Masalah}

1. Apakah terdapat pengaruh antara promosi dengan peningkatan jumlah siswa pada tahun ajaran baru pada SDIT Bina Cendekia? 
2. Apakah peningkatan promosi dapat meningkatkan jumlah siswa pada tahun ajaran baru pada SDIT Bina Cendekia?

3. Apakah terdapat pengaruh pada peningkatan jumlah siswa pada tahun ajaran baru setelah dilakukan proses promosi pada SDIT Bina Cendekia?

\section{Tujuan Penelitian}

1. Untuk mengetahui pengaruh dan hubungan antara promosi dengan peningkatan jumlah siswa pada tahun ajaran baru pada SDIT Bina Cendekia

2. Untuk mengetahui peningkatan promosi dalam meningkatkan jumlah siswa pada tahun ajaran baru pada SDIT Bina Cendekia.

3. Untuk mengetahui pengaruh peningkatan jumlah siswa pada tahun ajaran baru setelah dilakukan proses promosi pada SDIT Bina Cendekia.

\section{Manfaat Penelitian}

Adapun manfaat dari penelitian ini adalah:

1. Manfaat praktis

Penelitian ini diharapkan dapat memberikan sumbangan pemikiran dan mengungkapkan masalah yang timbul serta saran-saran untuk memecahkannya, dan mengetahui sejauh mana kemampuan praktis sehingga pada akhirnya dapat memberikan manfaat kepada sekolah untuk terus maju dan berkembang.

2. Manfaat teoritis

Penelitian ini merupakan kelanjutan dari proses belajar mengajar dalam rangka mencoba menerapkan ilmu yang pernah penulis terima dengan keadaan dilapangan, sehingga penulis harapkan dengan penelitian ini dapat menjadi pengalaman dan mengetahui sejauhmana kemampuan teoritis tersebut dapat diterapkan dalam praktek sehari-hari. Melalui penelitian ini di harapkan dapat memberikan sumbangan terhadap perkembangan ilmu pengetahuan, khususnya dalam ilmu manajemen pemasaran.

\section{METODE PENELITIAN}

Tempat Penelitian ini dilakukan pada SDIT Bina Cendekia yang beralamat di Jalan Raya Curug RT 01 /RW 09, Kecamatan Bojongsari Kota Depok. Penelitian dilakukan mulai dari November 2019 sampai dengan Januari 2020 tentang pengaruh promosi terhadap keputusan memilih sekolah pada orangtua siswa SDIT Bina Cendekia - Depok. Tujuan penelitian ini adalah untuk mengetahui pengaruh promosi terhadap peningkatan jumlah siswa pada tahun ajaran baru di SDIT Bina Cendekia. Metode yang digunakan adalah metode deskriptif kuantitatif. Teknik sampling yang digunakan adalah random sampling menggunakan sampel jenuh sebanyak 143 responden. Analisis data menggunakan Uji Validitas, Uji Reliabilitas Instrumen, Uji Korelasi Product Moment, Uji Regresi Sederhana, Uji Koefisien Determinasi dan Uji Hipotesis.

\section{HASIL PENELITIAN DAN PEMBAHASAN}

\section{a. Uji Korelasi Product Moment}

Uji korelasi product moment adalah untuk menguji hipotesis hubungan antara satu variabel independen dengan satu variabel dependen. Untuk mengetahui seberapa kuat hubungan korelasi antar variabel adalah dengan menggunakan rumus product moment (Pearson).

Selanjutnya hasil dari korelasi tersebut diinterprestasikan dengan tabel pedoman korelasi untuk mengetahui kekuatan hubungan antar variabel. 
Tabel 1

Pedoman Untuk Memberikan Interpretasi Koefisien Korelasi

\begin{tabular}{|c|c|c|}
\hline No & Tingkat Hubungan & Tingkat Hubungan \\
\hline 1 & $0,00-0,199$ & Sangat Rendah \\
\hline 2 & $0,20-0,399$ & Rendah \\
\hline 3 & $0,40-0,599$ & Sedang \\
\hline 4 & $0,60-0,799$ & Kuat \\
\hline 5 & $0,80-1,000$ & Sangat Kuat \\
\hline
\end{tabular}

Sumber : Sugiyono (2015:250)

Berikut hasil output uji korelasi product moment menggunakan bantuan software SPSS versi 24 adalah sebagai berikut :

\begin{tabular}{|c|c|c|c|c|}
\hline \multicolumn{5}{|c|}{ Model Summary } \\
\hline Model & $\mathrm{R}$ & R Square & $\begin{array}{c}\text { Adjusted R } \\
\text { Square }\end{array}$ & $\begin{array}{l}\text { Std. Error of the } \\
\text { Estimate }\end{array}$ \\
\hline 1 &, $430^{\mathrm{a}}$ &, 185 &, 179 & 4,225 \\
\hline
\end{tabular}

Berdasarkan tabel model summary ${ }^{b}$ di atas menunjukkan, nilai korelasi R sebesar 0,430 nilai ini masuk ke dalam rentang antara 0,400 - 0,599 dengan tingkat hubungan sedang, maka dapat disimpulkan bahwa, variabel Disiplin Promosi (X) memiliki tingkat hubungan Sedang terhadap variabel Minat Sekolah (Y).

\section{b. Uji Koefisien Determinasi}

Koefisien determinasi adalah kadar kontribusi variabel bebas terhadap variabel terikat. Koefisien determinasi dilambangkan $\mathrm{r}^{2}$. Rumus koefisien determinasi adalah KD $=\mathrm{r}^{2} \times 100 \%$

Berikut hasil output uji koefisien determinasi menggunakan bantuan software SPSS versi 24 adalah sebagai berikut :

\begin{tabular}{|c|c|c|c|c|}
\hline \multicolumn{5}{|c|}{ Model Summary $^{b}$} \\
\hline Model & $\mathrm{R}$ & R Square & $\begin{array}{l}\text { Adjusted R } \\
\text { Square }\end{array}$ & $\begin{array}{l}\text { Std. Error of the } \\
\text { Estimate }\end{array}$ \\
\hline 1 &, $430^{\mathrm{a}}$ &, 185 & ,179 & 4,225 \\
\hline
\end{tabular}

Berdasarkan tabel model summary ${ }^{b}$ di atas menunjukkan, R Square sebesar 0,185 $(0,185 \times 100 \%=18,5 \%)$ maka dapat disimpulkan bahwa, Promosi (X) memiliki Kontribusi atau sumbangan terhadap Minat sekolah (Y) sebesar 18,5\% dan sisanya 81,5\% dipengaruhi oleh faktor lain yang tidak diteliti.

\section{c. Uji Hipotesis Parsial}

Hipotesis merupakan jawaban atau dugaan sementara yang harus di uji kebenarannya. Dalam penelitian ini terdiapat 2 (dua) variabel yaitu Promosi (X) dan Minat sekolah (Y), dan uji dikarenakan terdapat 2 (dua) variabel maka uji hipotesis yang digunakan adalah uji Hipotesis Parsial (t-test).

Adapun hipotesis yang akan di uji kebenarannya adalah :

$\mathrm{H}_{0}$ : Tidak terdapat pengaruh positif dan signifikan antara promosi sekolah terhadap minat sekolah pada SD Bina cendekia

$\mathrm{H}_{\mathrm{a}}$ : $\quad$ Terdapat pengaruh positif dan signifikan antara promosi sekolah terhadap minat sekolah pada SD Bina cendekia.

Kriteria pengambilan keputusan dalam uji hipotesis parsial adalah :

Menentukan $t_{\text {tabel }}$ dengan ketentuan :

Taraf error $(\alpha)=5 \%$

Taraf nyata $\quad=95 \%$ 


\begin{tabular}{|c|c|c|}
\hline $\mathrm{n}$ & $=143$ & Jumlah sampel responden \\
\hline $\mathrm{dk}$ & $=\mathrm{n}-2$ & Derajat kebebasan \\
\hline $\mathrm{dk}$ & $=143-$ & \\
\hline $\mathrm{t}$ tabel $(\alpha, \mathrm{n}-2)$ & $=5 \%, 1$ & \\
\hline $\mathrm{t}$ tabel $(5 \%, 141)$ & $=1,977$ & \\
\hline
\end{tabular}

Prosedur pengujian sebagai berikut :

1) Jika $t_{\text {hitung }} \leq \mathrm{t}_{\text {tabel }} 1,977$ dengan taraf $5 \%$ maka $\mathrm{H}_{0}$ diterima dan $\mathrm{H}_{\mathrm{a}}$ ditolak

2) Jika $t_{\text {hitung }}>t_{\text {tabel }} 1,977$ dengan taraf $5 \%$ maka $\mathrm{H}_{\mathrm{a}}$ diterima dan $\mathrm{H}_{0}$ ditolak

Berikut hasil output uji hipotesis parsial menggunakan bantuan software SPSS versi 24 adalah sebagai berikut:

\begin{tabular}{|c|c|c|c|c|c|c|}
\hline \multicolumn{7}{|c|}{ Coefficients $^{\mathbf{a}}$} \\
\hline & & \multicolumn{2}{|c|}{ Unstandardized Coefficients } & $\begin{array}{l}\text { Standardized } \\
\text { Coefficients }\end{array}$ & \multirow[b]{2}{*}{$\mathrm{t}$} & \multirow[b]{2}{*}{ Sig. } \\
\hline \multicolumn{2}{|c|}{ Model } & $\mathrm{B}$ & Std. Error & Beta & & \\
\hline \multirow[t]{2}{*}{1} & (Constant) & 21,071 & 3,443 & & 6,119 &, 000 \\
\hline & Promosi $(\mathrm{X})$ & ,755 & , 134 & 430 & 5,653 &, 000 \\
\hline
\end{tabular}

a. Dependent Variable: Minat Sekolah (Y)

Berdasarkan tabel Coefficients ${ }^{a}$ di atas menunjukkan nilai $\mathrm{t}_{\text {hitung }} 5,653>\mathrm{t}_{\text {tabel }} 1,977$ dengan taraf $5 \%$ maka $\mathrm{H}_{\mathrm{a}}$ diterima dan $\mathrm{H}_{0}$ ditolak maka dalam penelitian ini menetapkan Bahwa Terdapat Pengaruh Positif Dan Signifikan Antara Promosi sekolah (X) Terhadap Minat Sekolah (Y) Pada SD Bina Cendikia.

\section{PENUTUP}

\section{A. Kesimpulan}

1. Berdasarkan distribusi jawaban variabel Promosi Sekolah (X) yang terdiri dari 6 (enam) instrument, maka dapat disimpulkan bahwa, Promosi Sekolah (X) saat ini sudah berjalan dengan Baik. Baiknya Promosi Sekolah ini juga di lihat dari persentase skor jawaban yang menjawab Sangat Setuju (SS) sebesar 4,39\% skor jawaban Setuju (S) sebesar 4,23\%, skor jawaban Ragu-Ragu (RR) sebesar 0,52\%, skor jawaban Tidak Setuju (TS) sebesar 0,29\% dan skor jawaban Sangat Tidak Setuju (STS) sebesar 0,57\%.

2. Berdasarkan distribusi jawaban variabel Minat Sekolah (Y) yang terdiri dari 10 (Sepuluh) instrument, maka dapat disimpulkan bahwa, Minat Sekolah (Y) saat ini sudah berjalan dengan Baik. Baiknya Minat ini juga di lihat dari persentase skor jawaban yang menjawab Sangat Setuju (SS) sebesar 42,7\% skor jawaban Setuju (S) sebesar 4,27\%, skor jawaban Ragu-Ragu (RR) sebesar 0,30\%, skor jawaban Tidak Setuju (TS) sebesar 3,1\% dan skor Jawaban Sangat tidak Setuju (STS) sebesar 0,6\%.

3. Berdasarkan analisa data menunjukkan bahwa Terdapat Pengaruh Positif dan Signifikan antara Promosi Sekolah (X) terhadap Minat Sekolah (Y) pada SDIT Bina Cendekia. dapat disimpulkan bahwa, Promosi Sekolah(X) memiliki Kontribusi atau Sumbangan terhadap Minat Sekolah (Y) sebesar 18,48\% dan sisanya 81,52\% dipengaruhi oleh faktor lain yang tidak diteliti. Uji hipotesis parsial menunjukkan nilai thitung 5,6528 > t tabel 1,977 dengan taraf 5\% maka Ha diterima dan $\mathrm{H} 0$ ditolak maka dalam penelitian ini menetapkan bahwa Terdapat Pengaruh Positif dan Signifikan antara Promosi Sekolah (X) terhadap Minat Sekolah (Y) pada SDIT Bina Cendekia. 


\section{B. Saran}

Pada kesempatan ini, peneliti ingin memberikan sumbangsih saran dan solusi untuk SDIT Bina Cendekia guna penyempurnaan promosi dan peningkatan keputusan memilih sekolah SDIT Bina Cendekia. Beberapa saran yang dapat peneliti berikan, sebagai berikut :

1. SDIT Bina Cendekia selaku penyedia jasa pendidikan harus meningkatkan promosi sekolah kepada bagian marketing agar selalu menginformasikan kepada orangtua siswa tentang produk sekolah, misalnya dengan menawarkan kepada para orangtua untuk memilih sekolah serta memasang pamplet maupun banner sekolah ditempat yang mudah dilihat oleh orangtua.

2. Dalam meningkatkan keputusan orangtua siswa untuk memilih sekolah pada SDIT Bina Cendekia-Depok, sekolah sebaiknya menentukan strategi agar orangtua siswa tetap setia dalam memilih sekolah SDIT Bina Cendekia, misalnya dengan memberikan promosi tentang peningkatan siswa yang masuk pada tahun ajaran baru, promosi yang diberikan bisa dengan diskon, promosi dengan memberikan hadiah dalam mengadakan perlombaan pada open house atau dengan promosi lainya. Hal ini dilakukan agar orangtua siswa tidak tertarik oleh sekolah lain yang menjadi kompetitior SDIT Bina Cendekia.

\section{DAFTAR PUSTAKA}

Arikunto, 2010, Prosedur Penelitian: Suatu Pendekatan Praktis. Edisi Revisi, Rineka Cipta. Jakarta.

Assauri, 2012, Manajemen Pemasaran, Rajawali Pers, Jakarta.

Atik dan Ratminto, 2012, Manajemen Pelayanan. Pustaka Pelajar, Yogyakarta.

Daryanto, 2011, Strategi Menaklukkan. Pasar Melalui Riset Ekuitas dan Perilaku Merek. Cetakan Ketiga. Gramedia, Jakarta.

D Prasada, S Sarwani, M Catio. (2019). Pengaruh Kompensasi Dan Lingkungan Kerja Terhadap Kinerja Karyawan Pada PT. Mitra Adiperkasa, Tbk. Jurnal Manajemen, Bisnis dan Organisasi (JUMBO) 3 (3), 195-20765.

D Sunarsi. (2014). Pengaruh Gaya Kepemimpinan, Motivasi dan Disiplin Kerja Terhadap Kinerja Pendidik. Universitas Pamulang.

Effendi M. Guntur, 2010, Transformasi Manajemen Pemasaran+Membangun. Citra Negara. Sagung Seto, Jakarta.

Ghozali, 2012, Aplikasi Analisis Multivariate Dengan Program SPSS. Badan Penerbit Undip. Semarang.

Gumilar, I., Sunarsi, D. (2020). Comparison of financial performance in banking with high car and low car (Study of banks approved in the kompas 100 index for the period 20132017). International Journal of Psychosocial Rehabilitation. Volume 24 - Issue 7.

Hasibuan, 2009, Manajemen Sumber Daya Manusia, Edisi Revisi, PT Bumi Aksara, Jakarta. Hasan, 2009, Marketing, Media Pressindo, Yogyakarta.

Jhon D. Millet, 2012, Management in the public service: The quest for effective performance. New York: McGraw-Hill.

Kotler dan Amstrong, 2012, Prinsip-Prinsip Pemasaran Jilid I. Erlangga, Jakarta.

Maddinsyah, A., Sunarsi, D., Hermawati, R., Pranoto. (2020). Analysis of location selection effect on the user decision that influcence the success of the service business of micro, small and medium enterprise (MSME) in bandung timur region. International Journal of Advanced Science and Technology. Vol. 29 No. 06

Munarsih, (2019). Analisis Strategi Pelaksanaan Pelayanan Pendidikan pada SDIT Bina Cendekia - Depok. Jurnal Kompetitif, Vol 2, No. 3, 136-155. 
Munarsih, Mada F. Akbar, Ariyanto, A., Ivantan, Sudarsono, A. (2020). Pelatihan Digital Marketing dalam Meningkatkan Kompetensi Siswa untuk Berwirausaha pada SMK Muhammadiyah Parung-Bogor. Jurnal Pengabdian Dharma Laksana, Vol 3, No. 1, 22-27.

Purwanti, P., Sarwani, S., \& Sunarsi, D. (2020). Pengaruh Inovasi Produk Dan Brand Awareness Terhadap Keputusan Pembelian Konsumen Pada Pt. Unilever Indonesia. Inovasi, 7(1), 24-31.

Putranto, A. T., Widodo, A. S., Hanny, R., Septiani, F., \& Armansyah, A. (2020). Melalui PkM Universitas Pamulang: Mari Kita Tingkatkan Jejaring Pemasaran POSYANTEK dalam Menyongsong Era Industri 4.0. Abdi Laksana, 1(2).

Rangkuty, 2009, Riset Pemasaran, Gramedia pustaka Utama, Jakarta.

Robbins dan Coulter, 2014, Manajemen, Edisi ke sepuluh jilid 1, Erlangga, Jakarta.

Rosvita, 2010, Analisis Pengaruh Kualitas Produk, Harga, Promosi, dan Cuaua terhadap Keputusan Pembelian Teh siap Minum dalam Kemasan Merek Teh Botol Sosro. Fakultas Ekonomi Universitas Diponegoro Semarang.

Saladin, 2011, Manajemen Strategi dan Kebijakan Perusahaan, Edisi Lima, Linda Karya, Bandung.

Shinta Agustina, 2011, Perilaku Konsumen : Afeksi Konsumen, Lab, Manajemen Agribisnis/Fakultas Pertanian, Universitas Brawijaya, Malang.

Sudjana, 2001, Metode \& Teknik Pembelajaran Partisipatif, Falah Production, Bandung.

Sugiyono, 2015, Metodologi Penelitian Manajemen, Alfabeta, Bandung.

Sunarsi, D., \& Asmalah, L. (2018). Pelatihan Manajemen Pengembangan Diri Bagi Penerima Beasiswa RZIS UGM Dan Dompet Shalahuddin Jogjakarta. Jurnal Pengabdian Dharma Laksana, 1(1), 51-60.

Sunarsi, D., \& Erlangga, A. (2020). The Effect of Leadership Style and Work Environment on the Performance of Stationary Pump Operators in the Water Resources Office of West Jakarta City Administration. International Journal of Advances in Social and Economics, 2(3).

Sunasi, D., Kusjono, G., \& Nuryana, I. (2019). Pelatihan Manajemen Penguasaan Kelas Dan Pembuatan Bahan Ajar Bagi Tenaga Pengajar Sukarela Taman Belajar Kreatif Mekarsari. Jurnal Pengabdian Dharma Laksana, 2(1), 41-44.

Supardi, 2013, Aplikasi Statistik Dalam Penelitian, PT Prima Ufuk Semesta, Jakarta.

Supranto, 2012, Metode Riset Aplikasinya Dalam Pemasaran, Lembaga Penerbitan Fakultas Ekonomi Universitas Indonesia, Jakarta.

Susanto, J. (2012). Pengaruh Pemasaran Online. Harga dan Pelayanan Terhadap Keputusan Pembelian (Studi pada Website www. pagarkanopi. com). Tesis, Universitas Pamulang.

Tjiptono, 2014, Pemasaran Jasa, Andi Offset, Yogyakarta. 